\section{Effects of vegetable powders as nitrite alternative in Italian dry fermented sausage}

\author{
Luca Pennisi, Enrica Verrocchi, \\ Domenico Paludi, Alberto Vergara \\ Faculty of Veterinary Medicine, \\ University of Teramo, Località Piano \\ d'Accio, Teramo, Italy
}

\begin{abstract}
The aim of this work was to study the effects of reformulation of an Italian dry fermented sausage by replacing nitrite with celery or spinach powder alone or in combination with beet powder on some quality characteristics of the product. Five different sausage formulations were produced: i) Control negative $(\mathrm{CN})$ : no nitrate added; ii) Control positive (CP) 150 $\mathrm{mg} / \mathrm{kg}$ potassium nitrate; Group with celery powder (GSe): $3 \mathrm{~g} / \mathrm{kg}$ celery powder; iii) Group with celery powder and beet powder (GSeB): $3 \mathrm{~g} / \mathrm{kg}$ of celery and beet powder, respectively; iv) Group with spinach powder and beet powder (GSpB): $3 \mathrm{~g} / \mathrm{kg}$ of spinach and beet powder, respectively. There was no significant difference between the residual nitrite contents of the samples at the end of the storage period. From microbiological analysis no target pathogenic bacterium has been isolated and the lactic bacteria microflora showed a similar trend in all of the lots.

Suggested storage periods for CP, GSe and $\mathrm{GSeB}$ were over 60 days by taking into consideration the microbiology and sensory evaluation. Sensory evaluation scores of samples with celery powder, in fact, were comparable to those of $\mathrm{CP}$ during storage. The GSpB samples showed similar and higher values regarding the structural attributes, the related attribute to colour showed decidedly lower values due to a greenish coloration of the slice to the presence of spinach.
\end{abstract}

\section{Introduction}

The production of dry fermented sausage involves the use of salt, nitrite, nitrate and various spices in order to provide the product with a preservative effect and improve its colour, aroma, texture and taste (Aksu and Kaya, 2002; Parthasarathy and Bryan, 2012). Nitrites and nitrates are widely used in meatbased products to promote an antimicrobial effect against some pathogens e.g. Clostridium botulinum, for the development of characteristic colours and flavours and for their antioxidant effect (Shahidi and Pegg, 1992; Sindelar et al., 2007). However, nitrites reacting with secondary or tertiary amines in meat could form carcinogenic, teratogenic and mutagenic $\mathrm{N}$-nitrous compounds. In October 2015, the International Agency for Research on Cancer (IARC), the cancer agency of the World Health Organization, evaluated the carcinogenicity of the consumption of red meat and processed meat.

The processing meat was classified as carcinogenic to humans (Group 1), based on sufficient evidence in humans that the consumption of these products causes colorectal cancer (Bouvard et al., 2015; IARC, 2015).

Following the echo produced by this evaluation, the consumption of processed meat collapsed. Therefore, in recent years, studies on the replacement of synthetic nitrates with natural homologues have increased (Horsch et al., 2014; Kim et al., 2017; Magrinyà et al., 2009; Riel et al., 2017; Sindelar et al., 2007; Tsoukalas et al., 2011).

In fact, natural nitrates are considered more functional for their purpose for two reasons; firstly, the nitrate concentrations entering and those residues can be lower than the synthetic homologues and, moreover, they can be admitted as an organic ingredient.

Celery, in concentrated juice or powder, is the most widely used additive as a source of nitrates in studies with meat-based products (Horsch et al., 2014; Magrinyà et al., 2009; Myers et al., 2013; Sebranek et al., 2014; Sucu and Yildiz, 2018; Tahmouzi et al., 2011; Usinger et al., 2016). Some commercially available juices show a content of 2114 ppm, 2273 ppm and 3227 ppm of nitrate respectively for celery, beet and spinach (Sebranek and Bacus, 2007).

For their use, however, plant nitrates must first be reduced to nitrites by specific microorganisms, coagulase-negative cocci such as Kocuria varians, Staphylococcus xylosus, Staphylococcus carnosus and others (Sebranek and Bacus, 2007).

The objective of this study was to evaluate the possibility of using some vegetable powders as an alternative to nitrates in the production of a dry fermented sausage, assessing its hygienic, sanitary, sensorial and qualitative characteristics.

\section{Materials and Methods}

\section{Production of vegetable powders}

Organic celery and spinach leaves were
Correspondence: Luca Pennisi, Facoltà di Medicina Veterinaria, Università di Teramo, Località Piano d'Accio, 64100 Teramo, Italy. Tel. +39.0861.166886

E-mail:1mpennisi@unite.it

Key words: Celery powder; spinach powder; dry fermented sausage; nitrite alternative.

Contributions: All the authors contributed equally.

Conflict of interests: The authors declare no potential conflict of interests.

Funding: The work was supported by the Carispaq Foundation.

Received for publication: 24 July 2019.

Revision received: 22 November 2019.

Accepted for publication: 27 November 2019.

This work is licensed under a Creative Commons Attribution-NonCommercial 4.0 International License (CC BY-NC 4.0).

(C) Copyright: the Author(s), 2020

Licensee PAGEPress, Italy

Italian Journal of Food Safety 2020; 9:8422

doi:10.4081/ijfs.2020.8422

obtained from a local marketplace in Teramo, Italy. The vegetables were washed, cut and dried in a dry stove with the following parameters: $100^{\circ} \mathrm{C}$ for $2 \mathrm{~h}$ and $60^{\circ} \mathrm{C}$ for additional $4 \mathrm{~h}$. The dried celery and spinach were subsequently subjected to grinding and sieving. To avoid contamination of salami with spoilage or pathogenic microorganisms, the powders were pasteurized at $131^{\circ} \mathrm{C}$ for 10 seconds (Montiel-Flores et al.,2013). On the celery and spinach powders, before their use in the mixture, the quantity of nitrates was measured by means of the colorimetric method with MQuant ${ }^{\mathrm{TM}}$ test strips (Merck, Germany) and with bench photometer mod. HI 83200 (Hanna Instruments, Italy).

\section{Production of dry fermented sausage}

At the Pingue Group sausage factory (Sulmona, Italy) $150 \mathrm{~kg}$ of mixture (meat and fat cuts) were processed to prepare five different batches (each weighing $30 \mathrm{~kg}$ ) of seasoned raw sausages (Table 1).

The five different sausage formulations were: Control negative $(\mathrm{CN})$ no nitrate added; Control positive (CP) $150 \mathrm{mg} / \mathrm{kg}$ potassium nitrate; Group with celery powder (GSe) $3 \mathrm{~g} / \mathrm{kg}$ celery powder. Based on Sindelar et al. (2006), a mild effect on the colour of the meat was expected from celery and spinach, and beet powder was added in 
two lots.

Group with celery powder and beet powder (GSeB): $3 \mathrm{~g} / \mathrm{kg}$ of celery and beet powder, respectively; Group with spinach powder and beet powder (GSpB): $3 \mathrm{~g} / \mathrm{kg}$ of spinach and beet powder, respectively.

Samples were taken in the following way:

- Day 0: $150 \mathrm{~g}$ of mixture from each batch were taken before filling;

- Day 7: 3 samples from each batch have been taken at the end of the drying phase;

- Day 30: 3 samples from each batch were taken in the middle of the seasoning period, carried out in 60 days as established in agreement with the Producer;

- Day 60: at the end of the curing period all the samples of dry fermented sausages, belonging to the five lots, were taken and used for the pre-established analyses.

\section{Physicochemical analysis}

Weight determination: except for the mixture, the three samples for each lot, before the analysis, were weighed. The values, expressed in grams, represent the average of the three determinations.

$\mathrm{pH}$ determination: The $\mathrm{pH}$ was measured in 2 samples from each batch at the same analysis time $(0,7,30,60)$ after the microbial analysis. The $\mathrm{pH}$ measurement was carried out with $\mathrm{pH}$-meter mod. $\mathrm{pH}$ 330i/SET (WTW, Germany) with needle electrode. For each sample (10 $\mathrm{g}$ of sample and $90 \mathrm{ml}$ of distilled water) were carried out three measurements.

Water activity determination (Aw): the Aw was measured in 2 samples from each batch at the same analysis time $(0,7,30,60)$ after the microbial analysis. The Aw measurement was performed with AquaLab ${ }^{\circledR}$ model 3TE (Decagon Devices Inc., Washington). For each sample, three measurements were performed.

Residual nitrite analysis: on the finished products from each batch the residual nitrites content was determined by colorimetric method with MQuant TM test strips (Merck, Germany) and with a bench photometer mod. HI 83200 (Hanna Instruments, Italy).

\section{Microbiological analysis}

On all samples taken, microbiological analyses were performed to investigate the presence of the main useful and/or undesirable microorganisms present in fermented sausages, such as Total Mesophilic Count, lactic acid bacteria, Pseudomonas spp., Sulphite-reducing clostridia, Coagulase positive Staphylococci, Clostridium botulinum and Listeria monocytogenes.

The preparation of the test samples, the initial suspension and the decimal dilutions for the microbiological analysis was carried out using the UNI EN ISO 6887-1 method.

Subsequent isolations were conducted, instead, with the following methods: i) Total Mesophilic Count (TMC): Standard Plate Count Agar (PCA, Oxoid) incubated at $30^{\circ} \mathrm{C}$ for 48 hours (UNI EN ISO 4833);

Lactic acid bacteria (LAB): DeManRogosa-Sharpe Agar (MRS, Oxoid) incubated in microaerophilic atmosphere at $28^{\circ} \mathrm{C}$ for 72 hours (ISO 15214); ii) Pseudomonas spp: Pseudomonas Agar Base (Oxoid) supplemented with SR102E supplement (Oxoid) incubated at $22^{\circ} \mathrm{C}$ for 24 hours; iii) Sulphite-reducing clostridia: Sulfite Polymixine Sulfadiazide Agar (SPS, Oxoid) incubated at $37^{\circ} \mathrm{C}$ for 48 hours in anaerobiosis atmosphere; iv) Coagulase positive Staphylococci: Baird Parker with Rabbit Plasma Fibrinogen (Oxoid) incubated at $37^{\circ} \mathrm{C}$ for 48 hours (UNI EN ISO $6888-1$, 6888-2); v) Clostridium botulinum: AOAC method n. 977.26; vi) Listeria monocytogenes: Listeria Ottaviani Agosti Agar (bioMerieux) incubated at $37{ }^{\circ} \mathrm{C}$ for 24-48 hours (UNI EN ISO 11290-2).

The results, expressed as logarithm of colony-forming units per gram of analysed product $(\log \mathrm{cfu} / \mathrm{g})$, are the result of the average of the data obtained from three samples belonging to each lot.

\section{Sensory analysis}

Furthermore, for each type of finished product, an evaluation of the main attributes of sensorial interest was performed. This evaluation was entrusted to 25 habitual consumers of fermented sausages. The visual characteristics (colour, homogeneity of the mixture and compactness), the characteristics of the structure (tenderness and elasticity) and the olfactory-gustatory characteristics (odour, taste, aroma and chewiness) were evaluated. At the end of the evaluations, each panellist expressed a judgment of each sensory attribute using a 8point hedonic scale (8-like extremely, 1-dislike extremely).

\section{Statistical analysis}

The effects of vegetable powders and synthetic nitrate on the $\mathrm{pH}$ value, on lactic bacteria and on the sensory characteristics of the samples were analysed through a oneway ANOVA. The level of significance was set at $\mathrm{P}<0.05$. The data was analysed using the software Excel 2010 (Microsoft Corporation). The values were given in terms of average + standard error in the tables.

\section{Results and Discussion}

\section{Determination of nitrates in veg- etable powders and residual nitrite analysis}

The analysis showed a content of 50,000 ppm and 30,000 ppm of nitrates for celery powder and spinach powder, respectively. Similar values are reported in the bibliography. Sebranek et al. (2012) reports, in fact, that plants contain over $20,000 / 30,000 \mathrm{ppm}$ of nitrates and an addition to $0.3 \%$ per kilo of mixture, as applied in this project, can guarantee a supply of 45-60 ppm for celery powder and

Table 1. Composition of the five batches.

\begin{tabular}{|c|c|c|}
\hline Sample & Id sample & Composition \\
\hline Dry sausage without additive & $\mathrm{CN}$ & $\begin{array}{l}\text { Pork meat (shoulder), fat (belly), salt, pepper and starter culture } \\
\text { (Staphylococcus carnosus, Staphylococcus xylosus e Lactobacillus sakei) }\end{array}$ \\
\hline Dry sausage with commercial nitrite mixture & $\mathrm{CP}$ & $\begin{array}{l}\text { Pork meat (shoulder), fat (belly), salt, pepper, natural flavours, sodium ascorbate, } \\
150 \mathrm{mg} / \mathrm{Kg} \text { of potassium nitrate and starter culture (Staphylococcus carnosus, } \\
\text { Staphylococcus xylosus e Lactobacillus sakei) }\end{array}$ \\
\hline Dry sausage with celery powder & GSe & $\begin{array}{l}\text { Pork meat (shoulder), fat (belly), salt, pepper, } 3 \mathrm{~g} / \mathrm{Kg} \text { of celery powder and starter culture } \\
\text { (Staphylococcus carnosus, Staphylococcus xylosus e Lactobacillus sakei) }\end{array}$ \\
\hline Dry sausage whit celery and beet powder & GSeB & $\begin{array}{l}\text { Pork meat (shoulder), fat (belly), salt, pepper, } 3 \mathrm{~g} / \mathrm{Kg} \text { of celery powder, } 3 \mathrm{~g} / \mathrm{Kg} \text { of beet powder } \\
\text { and starter culture (Staphylococcus carnosus, Staphylococcus xylosus e Lactobacillus sakei) }\end{array}$ \\
\hline Dry sausage with spinach and beet powder & GSpB & $\begin{array}{l}\text { Pork meat (shoulder), fat (belly), salt, pepper, } 3 \mathrm{~g} / \mathrm{Kg} \text { of spinach powder, } 3 \mathrm{~g} / \mathrm{Kg} \text { of beet } \\
\text { powder and starter culture (Staphylococcus carnosus, Staphylococcus xylosus e Lactobacillus sakei) }\end{array}$ \\
\hline
\end{tabular}


spinach powder, respectively. The analysis on the finished product showed, with the methods of analysis used, for all batch with vegetable powders and for the batch with potassium nitrate, values of residual nitrites below the sensitivity limit.

\section{pH determination}

The average $\mathrm{pH}$ values are showed in Table 2. In general, the $\mathrm{pH}$ trend is similar for all 5 batches under examination: at the time of filling, it starts from average $\mathrm{pH}$ values between 5.62 and 5.9, however lower than 6 .

After the drying period, the $\mathrm{pH}$ drops at the day 7 between 5.32 and 5.46 values, probably due to the intense activity of the fermenting microflora.

In the samples analysed on the 30th day the $\mathrm{pH}$ values show an increase except for the $\mathrm{CP}$ and for GseB, which show values of 5.1 and 5.39, respectively.

At the end of the curing period, the $\mathrm{pH}$ values reflect what was observed on the 30th. The CP and the GSeB, in fact, show values that are generally lower than the other batches. However, no statistically significant difference in terms of lactic acid bacteria count was observed between the five batches during the study. The lowering of the $\mathrm{pH}$ and the maintenance of these values plays an important role in determining protein coagulation, contributing to the formation of colour and to the stability of the product from the microbiological point of view (Hui et al., 2006).

\section{Water activity (Aw)}

Slight differences between the different batches were observed. All the samples, except those produced with the use of nitrates $(\mathrm{CP})$, showed a decreasing trend until the end of the seasoning period, recording values of about 0.970 at the beginning of maturation and values of about 0.850 at the 60 th day.

The CP samples, since the seventh day, showed lower Aw values (0.950) than the other batches. After the 60th day, in fact, it had values of 0.8440 , on average less than
0.015 units compared to the other samples.

\section{Microbiological analysis}

The evolution of useful and pathogen microorganisms in the different batches offers useful information regarding the level

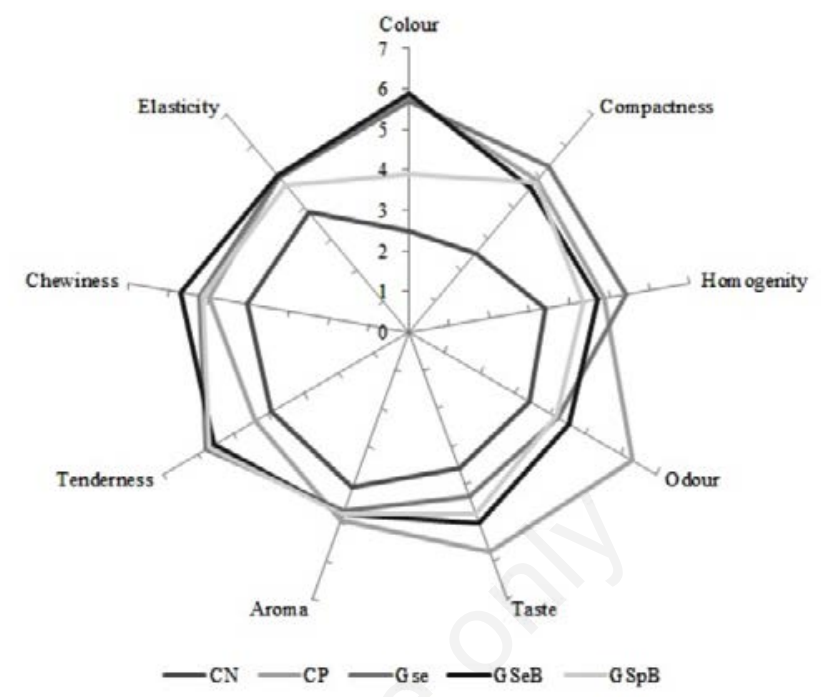

Figure 1. Sensorial scores of the fermented sausages.

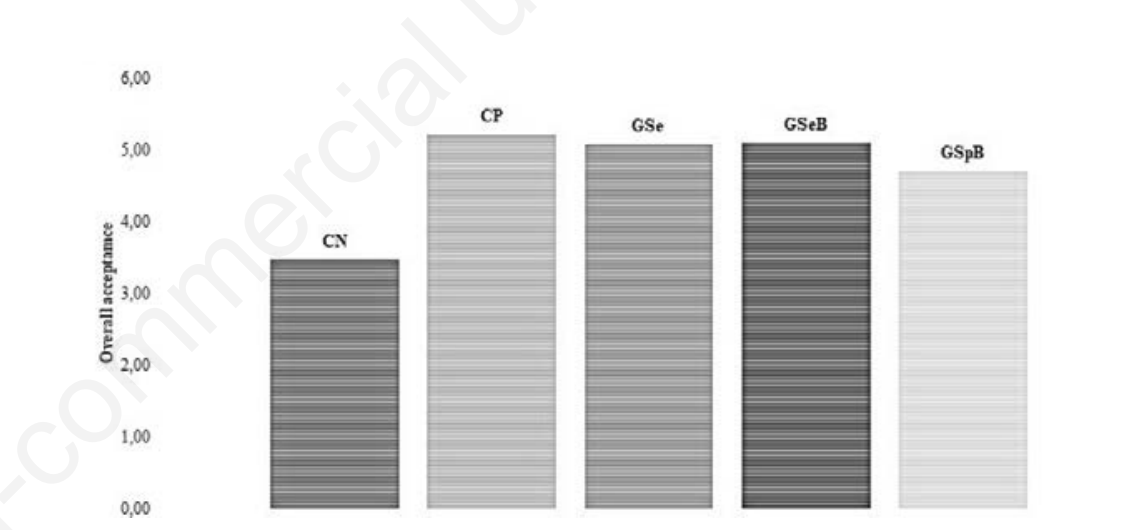

Figure 2. Overall acceptance scores of the fermented sausages.

Table 2. Average $\mathrm{pH}$ values of the fermented sausages during the production ( \pm standard error).

\begin{tabular}{lcccccc} 
Day & CN & CP & GSe & & GSeB & GSpB \\
0 & $5.9 \pm 0.28$ & $5.65 \pm 0.15$ & $5.66 \pm 0.01$ & $5.75 \pm 0.37$ & $5.62 \pm 0.13$ \\
7 & $5.32 \pm 0.30$ & $5.38 \pm 0.22$ & $5.32 \pm 0.08$ & $5.46 \pm 0.26$ & $5.43 \pm 0.19$ \\
\hline 30 & $5.66 \pm 0.30$ & $5.1 \pm 0.26$ & $5.56 \pm 0.00$ & $5.39 \pm 0.30$ & $5.68 \pm 0.20$ \\
60 & $6.25 \pm 0.32$ & $5.34 \pm 0.23$ & $6.02 \pm 0.09$ & $5.92 \pm 0.41$ & $6.05 \pm 0.16$ \\
\hline
\end{tabular}

Table 3. Average lactic bacteria microflora values $(\log \mathrm{CFU} / \mathrm{g})$ of the fermented sausages during the production ( \pm standard error).

\begin{tabular}{lcccccc} 
Day & CN & CP & GSe & GSeB & GSpB \\
0 & $3.40 \pm 0.08$ & $2.85 \pm 0.06$ & $4.92 \pm 0.12$ & $5.05 \pm 0.11$ & $5.05 \pm 0.11$ \\
7 & $5.92 \pm 0.02$ & $5.64 \pm 0.13$ & $6.68 \pm 0.02$ & $6.72 \pm 0.04$ & $6.74 \pm 0.04$ \\
\hline 30 & $8.44 \pm 0.05$ & $8.43 \pm 0.17$ & $8.44 \pm 0.04$ & $8.40 \pm 0.26$ & $8.43 \pm 0.12$ \\
60 & $9.03 \pm 0.23$ & $7.41 \pm 0.37$ & $8.79 \pm 0.41$ & $8.69 \pm 0.48$ & $8.92 \pm 0.13$ \\
\hline
\end{tabular}


of effectiveness of vegetable powder mixtures.

In general, it appears evident that the useful microorganisms are not affected by the presence of nitrites or nitrates or by the mixtures of natural extracts. As far as pathogen microorganisms are concerned, it must first be noted that the charges of Clostridium spp., Pseudomonas spp., Coagulase-positive staphylococci and Listeria monocytogenes were found to be undetectable for all samples during analysis interval. Similarly, the presence of sulphitereducing clostridia was below the analytical threshold.

The lactic bacteria microflora represented the microbial group most present during the entire seasoning period and showed a substantially similar trend in all the lots (Table 3).

However, no statistically significant difference in terms of lactic acid bacteria count was observed between the batches during the study.

\section{Sensory analysis}

The results of the sensory analysis are shown in Figures 1 and 2.

No statistical differences were observed between the batches during the study.

General approval preferred the nitrate lot (CP), however, the GSe and GSeB batches showed more than positive appreciation (Figure 3)

The attributes of smell, aroma and taste, in fact, showed greater appreciation in $\mathrm{CP}$, in Gse and in the GseB batches.

Regarding the structural attributes, such as chewability, elasticity and tenderness, the samples coming from the GSe, GSeB and GSpB lots showed similar and consistently higher values than those found by the samples coming from the CP.

The CN showed lower overall appreciation values than all the other batches.

Finally, the relative attribute to the colour showed decidedly lower values for

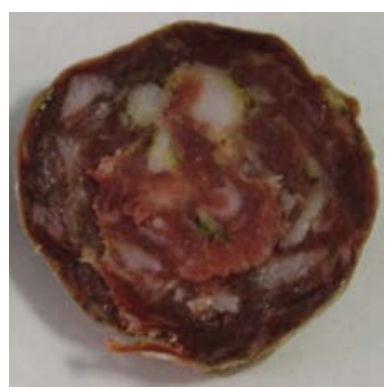

Figure 3. Detail of a slice from the GSpB batch (with spinach and beetroot powder). the lot with spinach and beetroot (GSpB) compared to a greenish coloration of the slice due, obviously, to the presence of spinach.

\section{Conclusions}

Clearly the nitrates of vegetable origin, in powder or in juice, offer a high potential as natural substitutes for nitrates and nitrites in processed meats. These, in fact, have shown the advantage of supplying nitrate in concentrated form without residual thresholds. Celery powder has also shown to be particularly suitable for the preparation of raw seasoned sausages, unlike spinach powder, since it did not affect the colour of the salami and gave it a slight aroma, which was particularly appreciated. At a time when consumers are being offered a wide variety of products without (without gluten, without palm oil, etc.), this research offers a product, or a series of products, in which the ingredients have their own identity. The use of vegetable powders, in fact, could create a niche of new products $100 \%$ natural, organic or even typical if not topical. The use of vegetable sources could be the reason to discover or rediscover ancient vegetable varieties such as the Sulmona red garlic or the Rivera lettuce of Aquila (ancient cultural variety of the historical gardens of Porta della Rivera)

\section{References}

Aksu M, Kaya M, 2002. Production of pastirma with different curing methods and using starter culture. Turkish Journal of Veterinary and Animal Sciences 26:909-16.

Bouvard V, Loomis D, Guyton KZ, Grosse Y, Ghissassi FE, Benbrahim-Tallaa L, Guha N, Mattock H, Straif K, 2015. Carcinogenicity of consumption of red and processed meat. The Lancet Oncology 16: 1599-600. https://doi.org/10.1016/S14702045(15)00444-1.

Horsch AM, Sebranek JG, Dickson JS, Niebuhr SE, Larson EM, Lavieri NA, Ruther BL,Wilson LA, 2014. The effect of $\mathrm{pH}$ and nitrite concentration on the antimicrobial impact of celery juice concentrate compared with conventional sodium nitrite on Listeria monocytogenes. Meat Sci 96: 400-7.

Hui YH, Nip WK, Nollet LML, Paliyath G, Simpson BK, 2006. Food biochemistry and food processing. 1st ed. Blackwell Publishing.
International Agency for Research on Cancer, 2015. Red meat and processed meat. IARC monograph on the evaluation of carcinogenic risks to humans 114.

Kim TK, Kim YB, Jeon KH, Park JD, Sung JM, Choi HW, Hwang KE, Choi YS, 2017. Effect of fermented spinach as sources of pre-converted nitrite on color development of cured pork loin. Korean J Food Sci Animal Resour 37:105-13.

Magrinyà N, Bou R, Tres A, Rius N, Codony R, Guardiola F, 2009. Effect of tocopherol extract, Staphylococcus carnosus culture, and celery concentrate addition on quality parameters of organic and conventional dry-cured sausages. J Agricult Food Chem 57:8963-72.

Montiel-Flores EE, Lòpez-Malo A, Bàrcenas Pozos ME, 2013. Vegetales como fuentes de nitritos: una alternative para el curado de carnes. Temas selectos de Ingenieria de Alimentos 7-1:57-67.

Myers K, Cannon J, Montoya D, Dickson J, Lonergan S, Sebranek JG, 2013. Effects of high hydrostatic pressure and varying concentrations of sodium nitrite from traditional and vegetable-based sources on the growth of Listeria monocytogenes on ready-to-eat (RTE) sliced ham. Meat Sci 94:69-76.

Parthasarathy DK, Bryan NS, 2012. Sodium nitrite: The "cure" for nitric oxide insufficiency. Meat Sci 92:274-9.

Riel G, Boulaaba A, Popp J, Klein G, 2017. Effects of parsley extract powder as an alternative for the direct addition of sodium nitrite in the production of mortadella type sausages-Impact on microbiological, physicochemical and sensory aspects. Meat Sci 131:166-75.

Sebranek JG, Bacus JN, 2007. Cured meat products without direct addition of nitrate or nitrite: What are the issues? Meat Sci 77:136-47.

Sebranek JG, Horsch A, Dickson J, Lavieri NA, Ruther B, 2014. The effect of $\mathrm{pH}$ and nitrite concentration on the antimicrobial impact of celery juice concentrate compared with conventional sodium nitrite on Listeria monocytogenes. Meat Sci 96:453-4.

Sebranek JG, Jackson-Davis AL, Myers KL, Lavieri NA, 2012. Beyond celery and starter culture: Advances in natural/organic curing processes in the United States. Meat Sci 92:267-73.

Shahidi F, Pegg RB, 1992. Nitrite-free meat curing systems: Update and review. Food Chem 43:185-91.

Sindelar JJ, Cordray JC, Sebranek JG, Love JA, Ahn DU, 2007. Effects of varying levels of vegetable juice powder and 
incubation time on color, residual nitrate and nitrite, pigment, $\mathrm{pH}$, and trained sensory attributes of ready-to-eat uncured ham. J Food Sci 72:388-95.

Sindelar JJ, 2006. Investigating uncured nonitrate-or-nitrite-added processed meat products. Ph.D. thesis. Iowa State University, Ames, IA, USA.

Sucu C, Yildiz GT, 2018. The investigation of the use of beetroot powder in Turkish fermented beef sausage (sucuk) as nitrite alternative. Meat Sci 140:158-66.
Tahmouzi S, Razavi SH, Safari M, EmamDjomeh Z, 2011. Development of a practical method for processing of nitrite-free hot dogs with emphasis on evaluation of physico-chemical and microbiological properties of the final product during refrigeration. J Food Process Pres 37:109-19.

Tsoukalas DS, Katsanidis E, Marantidou S, Bloukas JG, 2011. Effect of freeze-dried leek powder (FDLP) and nitrite level on processing and quality characteristics of fermented sausages. Meat Sci 87:140-5. Usinger EL, Larson EM, Niebuhr SE, Fedler CA, Prusa KJ, Dickson JS, Tarté R, Sebranek JG, 2016. Can supplemental nitrate in cured meats be used as a means of increasing residual and dietary nitrate and subsequent potential for physiological nitric oxide without affecting product properties? Meat Sci 121:324-32. 